\title{
Modal Analysis of Linear Mesoscale Convective System in Fujian Heavy Rainstorm
}

\author{
Hong Guo, Meijin Huang, Xingyu Wu, Wei Hong, Tingting Li \\ Fujian Meteorological Observatory, Fuzhou, China \\ Email: guohong45@126.com
}

How to cite this paper: Guo, H., Huang, M.J., Wu, X.Y., Hong, W. and Li, T.T. (2018) Modal Analysis of Linear Mesoscale Convective System in Fujian Heavy Rainstorm. Journal of Geoscience and Environment Protection, 6, 1-9. https://doi.org/10.4236/gep.2018.69001

Received: July 12, 2018

Accepted: August 26, 2018

Published: August 29, 2018

Copyright $\odot 2018$ by authors and Scientific Research Publishing Inc. This work is licensed under the Creative Commons Attribution International License (CC BY 4.0).

http://creativecommons.org/licenses/by/4.0/ (c) (i) Open Access

\begin{abstract}
This paper uses the daily precipitation observation data and Doppler weather radar observation data from 2017 observatories and regional automatic stations in Fujian, China from 2009 to 2015. The characteristics of formation mode, organization mode, moving direction and duration of linear mesoscale convective system during non-typhoon continuous rainstorm in Fujian were analyzed. This paper gives the definition of linear mesoscale convective systems, trailing and parallel mesoscale convective systems. The above characteristics of the linear mesoscale convective system during the continuous heavy rain in Fujian differ greatly from the non-sustained heavy rain process: The linear mesoscale convective system in the continuous heavy rain in Fujian is mainly constructed later, and the trailing and parallel mesoscale convective system is conducive to the occurrence of continuous heavy rain in Fujian. The moving direction of the linear mesoscale convective system and convective monomer is mainly in the east direction, and the system duration is mostly $4-10$ hours. The formation time of the monomer to form a linear convection time is mainly $1-3$ hours, which is 2 hours earlier than the organization process of the general linear mesoscale convective system. The linear convective system formed to a dead time of an average of 5 hours, slightly longer than the general linear mesoscale convective system.
\end{abstract}

\section{Keywords}

Sustained Heavy Rain in Fujian, Linear Mesoscale Convective System, Organizational Mode

\section{Introduction}

The mesoscale convective system (MCS) is a kind of weather system with small space-time scale. Its formation mode, organizational mode and structural evolu- 
tion directly determine the type, distribution and intensity of storm weather such as heavy rain [1] [2] [3]. Under the appropriate climate background, the occurrence of severe weather such as heavy rain is inseparable from the occurrence and development of MCS. MCS can be divided into linear type, irregular type and scorpion type, of which linear type MCS reaches 68\% [4]. According to radar reflectivity data (Figure 1), Bluestein et al. [5] subdivided the linear MCS into four types: broken type (BL), broken type (BA), rear built type $(\mathrm{BB})$ and embedded type (EA). Parker et al. [6] further classified 88 linear convective systems in the central United States based on the location of the layered clouds and convective zones: The layered cloud is located at the rear of the trailing type (TS), the layered cloud is located at the front of the leading type (LS) and the layered cloud is located at both sides of the parallel type (PS) (Figure 1(b)). Meng et al. [7] studied 96 linear convective cases in eastern China from 2008 to 2009, revealing that the linear MCS formation period is mostly broken during the heavy rain in eastern China, and the tailing type is dominant in the mature period.

Sustained heavy rains can easily lead to widespread floods and serious economic losses, which have been widely concerned in China [8] [9] [10]. However, previous studies have focused on the interannual and interdecadal characteristics of the continuous heavy rain process and the large-scale circulation situation. The study of meteorology is mainly based on case analysis or model simulation [11] [12] [13]. Based on the influence of MCS, the continuous heavy rain process is complex and variable. The characteristics of MCS in continuous heavy rain and the commonality of MCS in the context of different persistent rain events are worthy of further study. Studies have shown that [14] [15] [16], disconnected and post-built linear MCS is more conducive to the occurrence of persistent

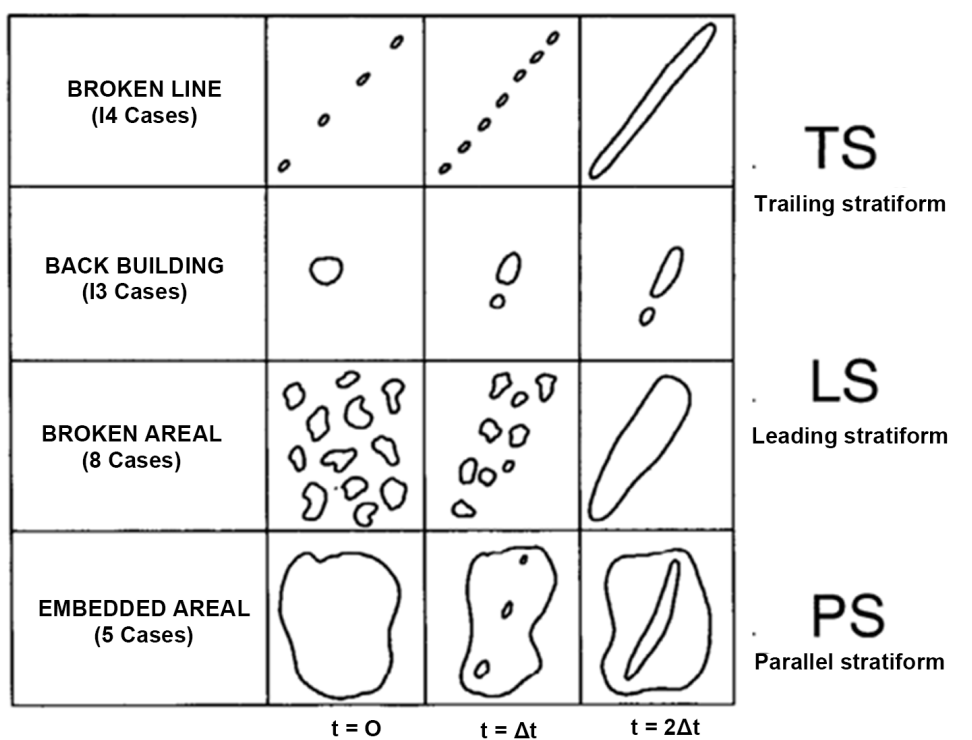

(a)
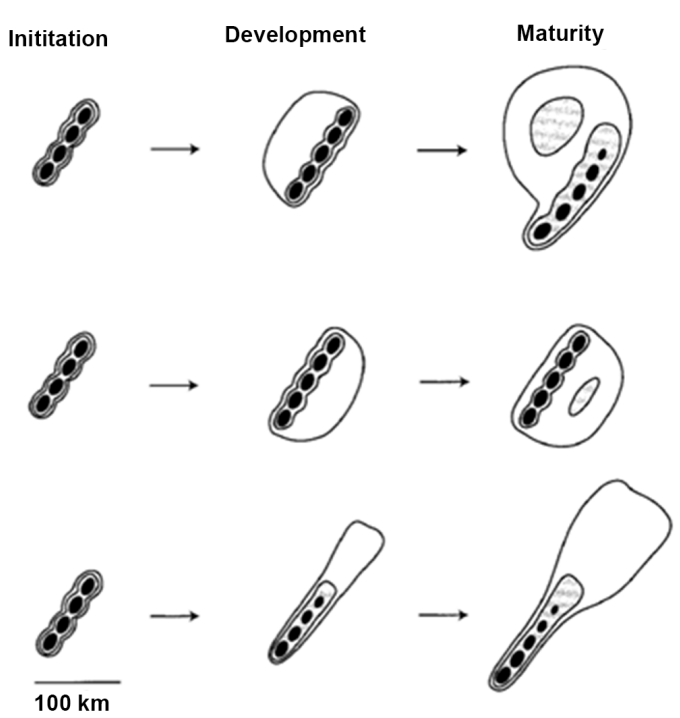

(b)

Figure 1. Formation mode (a) and tissue mode division of linear mesoscale convective system (b). 
heavy rain in the Guangdong and Guangxi regions. The movement of MCS is mainly in the east-northeast direction of the northeast and northeast, and the formation time is longer than the general linear MCS. What are the characteristics of MCS in the continuous heavy rain in Fujian, which is the scientific issue that is discussed in this paper? In the past, the continuous heavy rain research in Fujian used the base station data. Based on the observation data of daily observation stations in 2017 and regional automatic stations ranged from 2009 to 2015 in Fujian, the paper analyzed the characteristics of mesoscale convective system during the non-typhoon continuous heavy rain in Fujian. It reveals the characteristics of the type, formation and organization mode of the mesoscale convective system during the continuous heavy rain, and improves the forecast and early warning of severe weather.

\section{Research Areas, Data and Methods}

\subsection{Research Areas and Data}

This paper selects 2017 observation stations and regional automatic stations in Fujian area as Fujian representative stations (Figure 2). The main data used in this paper are: daily-time, hourly precipitation observation data and Doppler weather radar observation data of the Fujian regional automatic station from 2009 to 2015. Persistent rainstorms can be given different definitions from different focuses. This paper uses the name of Bao [2] on the definition of continuous rainstorm process in a single station: The daily precipitation is more than $50 \mathrm{~mm}$ for 3 consecutive days and above, or one day for 5 consecutive days, the precipitation is less than $50 \mathrm{~mm}$ and the remaining four days are greater than 50 $\mathrm{mm}$, and the precipitation is less than $50 \mathrm{~mm}$. This will ensure the continuity of the rainstorm process and ensure the extremity of continuous heavy rain. The torrential rain caused by the typhoon is not within the scope of this article because of its uniqueness. This paper aims to understand the characteristics of the mesoscale convective system in Fujian's non-typhoon continuous heavy rain from a common perspective, focusing on the persistence and catastrophicity of the non-typhoon continuous heavy rain process.

\subsection{Research Methods}

For the types and modal classification of MCS features during continuous heavy rain, the classification method of the literature in the introduction is used [7] [8] [9] [10].

The average daily precipitation of non-typhoon continuous rainstorms in $\mathrm{Fu}$ jian single station was distributed (Figure 3). In 2009-2015, there were 167 stations in 154 stations in Fujian, which showed continuous heavy rains at 167 stations, mainly in the coastal areas of the south central and northwest. The specific season, or specific months, in which the "heavy rain in Fujian" are given in Table 1. In terms of strength, the daily average precipitation of non-typhoon continuous heavy rain in Fujian single station is $50-75 \mathrm{~mm} / \mathrm{d}$ (79 stations, 


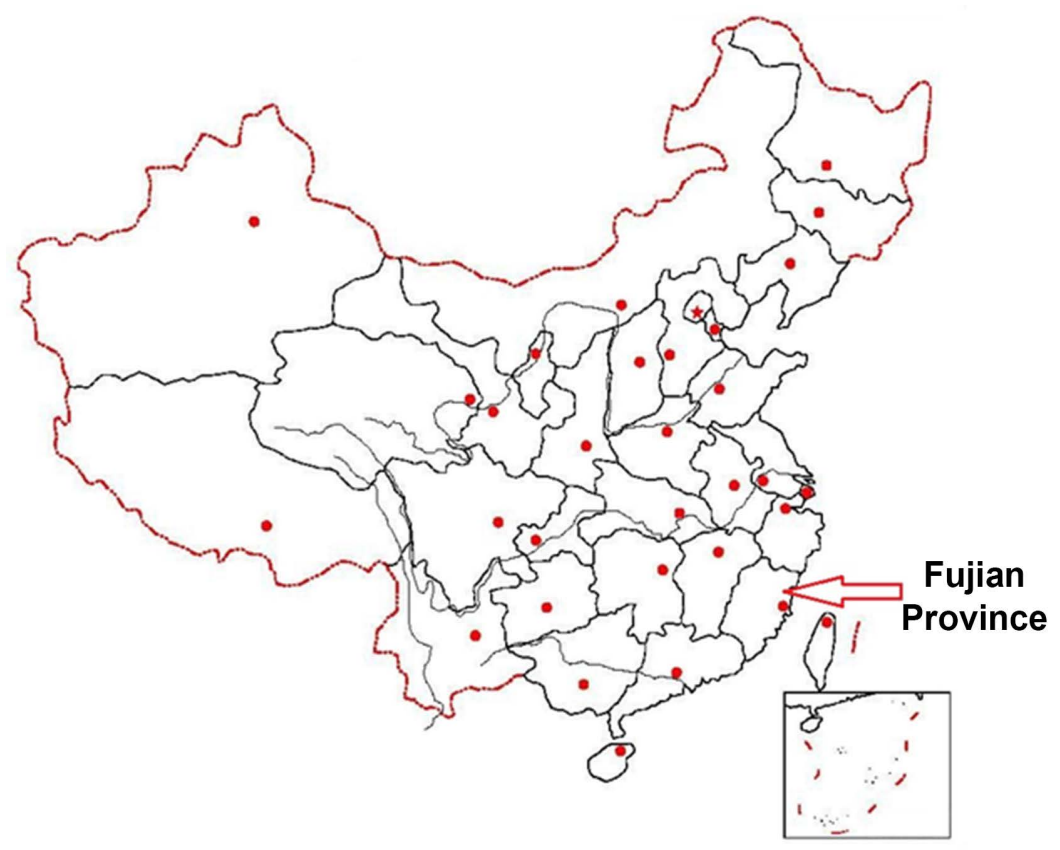

Figure 2. Location of Fujian Province in China.

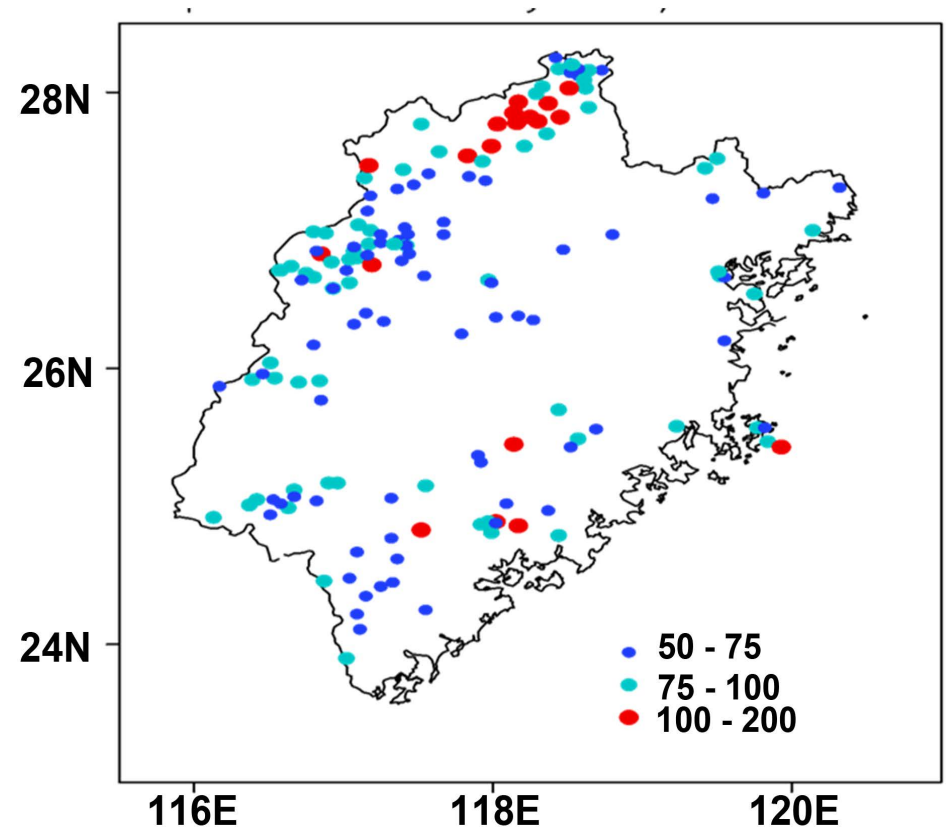

Figure 3. Daily average precipitation $(\mathrm{mm} / \mathrm{d})$ distribution of persistent heavy rain in Fujian single station.

accounting for 48\%), followed by $75-100 \mathrm{~mm} / \mathrm{d}$ (69 stations, accounting for $41 \%)$. Considering the coincidence of time (at least one day) and the proximity of the space to the site, except for the single station case, there were 15 non-typhoon continuous heavy rains in Fujian from 2009 to 2015. Each process contains 3 to 24 sites, the duration of the process is 3 days ( 7 cases), the occurrence time is 4 - 8 months, and the most cases in June (6 cases) (Table 1). 
Table 1. Non-typhoon continuous rainstorm process in Fujian from 2009 to 2015.

\begin{tabular}{cccc}
\hline Processes & Time & Duration/days & Number of Station \\
\hline 1 & Jul. 1-3, 2009 & 3 & 6 \\
2 & Jun. 13-17, 2010 & 5 & 12 \\
3 & Jun. 17-21, 2010 & 5 & 24 \\
4 & Jun. 21-25, 2010 & 5 & 24 \\
5 & Jun. 21-27, 2010 & 3 & 6 \\
6 & Jun. 5-7, 2011 & 3 & 4 \\
7 & Jun. 27-30, 2011 & 4 & 3 \\
8 & Jul. 15-18, 2011 & 4 & 6 \\
9 & Apr. 29-May 1, 2012 & 3 & 16 \\
10 & May 19-22, 2013 & 4 & 12 \\
11 & Apr. 24-26, 2014 & 3 & 3 \\
12 & May 14-19, 2014 & 6 & 5 \\
13 & Aug. 10-12, 2014 & 3 & 12 \\
14 & Jun. 9-11, 2015 & 3 & 11 \\
15 & Aug. 28-Sep. 2, 2015 & 6 & 5 \\
\hline
\end{tabular}

\section{Mesoscale Convective System Characteristics of Continuous Heavy Rainfall}

Table 2 reveals that 96 mesoscale convective systems occurred during 15 consecutive rainstorms, and a continuous heavy rain process consisted of $4-10$ mesoscale convective system processes. Among them, the number of mesoscale convective systems that occurred during the continuous heavy rain on May 14-19, 2014 was the highest (10 cases), which was related to its longer duration (6 days). Morphological characteristics, the mesoscale convective system causing persistent heavy rain (62 cases) reached 64\%, consistent with the results of Blanchard et al. (68\%) [4]. That is to say, the mesoscale convective system has no obvious relationship with the three types of prisoner type, fragment type and linear type, and whether it is conducive to continuous heavy rain.

Different from the parallel linear mesoscale convective system in the continuous heavy rain in South China [14], the proportion of tissue modal tailing in the continuous heavy rain in Fujian is much higher than that of parallel and leading. In 62 cases of linear MCS, 50\%, that is, trailing linear MCS is the most likely to cause persistent heavy rain in Fujian (Table 3). This is similar to the statistical results of Parker [6] and Meng [7] regarding linear MCS tissue modalities. In the modal form, 62 cases of linear mesoscale convective system were mainly built in the continuous heavy rain in Fujian (44\%), and the proportion of broken line type was less. This is quite different from the statistical results of Bluestein et al. [6], Meng et al. [5] and South China [14]. 
Table 2. Statistics of mesoscale convective systems during continuous heavy rainfall in Fujian.

\begin{tabular}{|c|c|c|c|c|}
\hline Time & Number of Systems & Prisoner & Fragment & Linear \\
\hline Jul. 1-3, 2009 & 6 & 0 & 2 & 4 \\
\hline Jun. 13-17, 2010 & 8 & 0 & 4 & 4 \\
\hline Jun. 17-21, 2010 & 8 & 1 & 1 & 6 \\
\hline Jun. 21-25, 2010 & 7 & 0 & 4 & 3 \\
\hline Jul. 25-27, 2010 & 4 & 0 & 3 & 1 \\
\hline Jun. 5-7, 2011 & 7 & 0 & 0 & 7 \\
\hline Jun. 27-30, 2011 & 5 & 0 & 1 & 4 \\
\hline Jul. 15-18, 2011 & 5 & 0 & 4 & 1 \\
\hline Apr. 29-May 1, 2012 & 7 & 0 & 1 & 6 \\
\hline May 19-22, 2013 & 5 & 0 & 0 & 5 \\
\hline Apr. 24-26, 2014 & 8 & 1 & 4 & 3 \\
\hline May 14-19, 2014 & 10 & 1 & 2 & 7 \\
\hline Aug. 10-12, 2014 & 5 & 0 & 3 & 2 \\
\hline Jun. 9-11, 2015 & 5 & 0 & 0 & 5 \\
\hline Aug. 28-Sep. 6, 2015 & 6 & 1 & 1 & 4 \\
\hline Total & 95 & 4 & 30 & 61 \\
\hline
\end{tabular}

Table 3. Formation of linear mesoscale convective system and comparison of histological modal characteristics.

\begin{tabular}{ccccccccc}
\hline Forming Mode & $\begin{array}{c}\text { Broken } \\
\text { Line (\%) }\end{array}$ & $\begin{array}{c}\text { After Construction } \\
(\%)\end{array}$ & $\begin{array}{c}\text { Fragment } \\
(\%)\end{array}$ & Embed (\%) & Organizational Mode & $\begin{array}{c}\text { Trailing } \\
(\%)\end{array}$ & $\begin{array}{c}\text { Parallel } \\
(\%)\end{array}$ & $\begin{array}{c}\text { Leading } \\
(\%)\end{array}$ \\
\hline $\begin{array}{c}\text { Sustained heavy rain in } \\
\text { Fujian }\end{array}$ & 28 & 44 & 18 & 10 & $\begin{array}{c}\text { Sustained heavy rain in } \\
\text { Fujian }\end{array}$ & 50 & 27 & 23 \\
$\begin{array}{c}\text { Sustained heavy rain in } \\
\text { South China [14] }\end{array}$ & 42 & 29 & 12 & 17 & $\begin{array}{c}\text { Sustained heavy rain in } \\
\text { South China [14] }\end{array}$ & 34 & 56 & 10 \\
$\begin{array}{c}\text { Bluestein and Jain [5] } \\
\text { Meng and Zhang [7] }\end{array}$ & 35 & 33 & 20 & 13 & Parker and Johnson [6] & 60 & 20 & 20 \\
\hline
\end{tabular}

The convective zone distribution of 62 linear mesoscale convective systems causing sustained heavy rain in Fujian was dominated by northeast-southwest (54 cases, 89\%). The direction of movement of the linear mesoscale convective system is dominated by the eastward direction (39 cases, accounting for $64 \%$ ). The movement of convective cells in the linear mesoscale convective system is consistent with the direction of convective movement, mainly in the eastward direction (37 cases, accounting for 66\%) and the northeast direction (10 cases, $16 \%)$. The consistency of the two movements may be one of the important reasons for the occurrence of persistent heavy rain (Figure 4), which is similar to the characteristics of the mesoscale convective system in the continuous heavy rain in South China [14].

The single-born to linear convective demise time of the linear mesoscale convective system in the continuous heavy rain in Fujian is mainly $4-10$ hours 


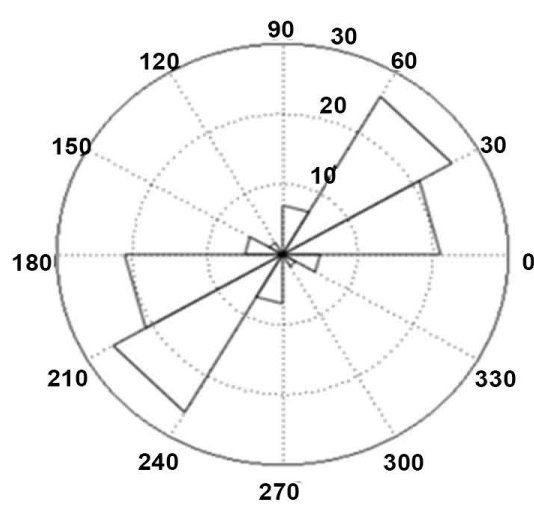

(a)

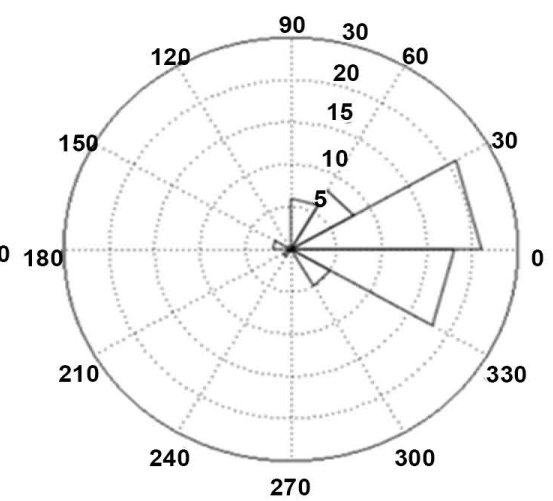

(b)

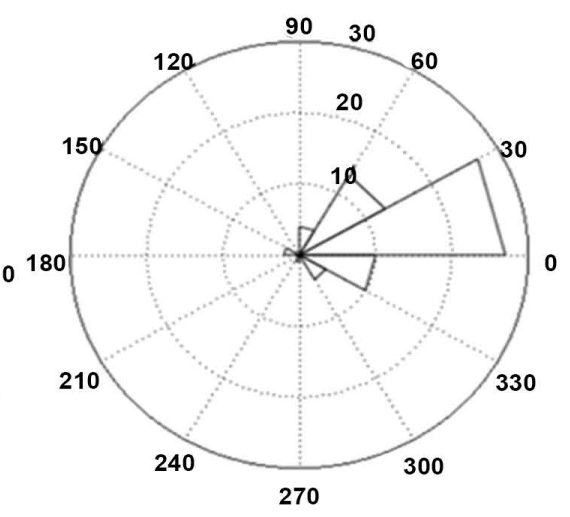

(c)

Figure 4. Convective zone direction (a), convective zone movement direction (b), and convective monomer movement direction distribution statistics of linear mesoscale convective systems (c).

(Figure 5). This is similar to Meng [7]'s statistical results for 96 linear convective processes in eastern China from 2008 to 2009. However, the monomer formation-forming linear convection time is usually $1-3$ hours, 2 hours earlier than the Meng [7] study results ( 3 - 5 hours). This is consistent with the convective monomer generation-forming linear convection time in the continuous heavy rain in South China [14]. At the same time, the linear mesoscale convective system formation-death time is mainly $2-8$ hours, with an average of 5 hours, which is 0.3 hours longer than the Meng [7] study results (4.7 hours). That is to say, the linear mesoscale convective system in the continuous heavy rain in $\mathrm{Fu}$ jian is more rapid, and the influence time after the formation of linear convection is longer, which is one of the possible causes of persistent heavy rain.

\section{Conclusions}

This paper uses the 2017 daily observation stations and regional automatic stations in Fujian from 2009 to 2015 to obtain daily precipitation observation data and South China Doppler radar observation data. The characteristics of formation mode, organization mode, moving direction, development and duration of linear mesoscale convective system during non-typhoon continuous heavy rain in Fujian were analyzed statistically. The main conclusions are as follows:

1) In 2009-2015, there were 167 stations in 154 stations in Fujian, which showed continuous heavy rains at 167 stations, mainly in the coastal areas of the south central and northwest.

2) The linear mesoscale convective system in the continuous heavy rain in Fujian is mainly constructed later, and the trailing and parallel mesoscale convective system is more conducive to the occurrence of continuous heavy rain in $\mathrm{Fu}$ jian.

3) The linear MCS convective direction in the continuous heavy rain in Fujian is mainly northeast-southwest, and the convective system and convective monomer moving direction are mainly in the east direction. 


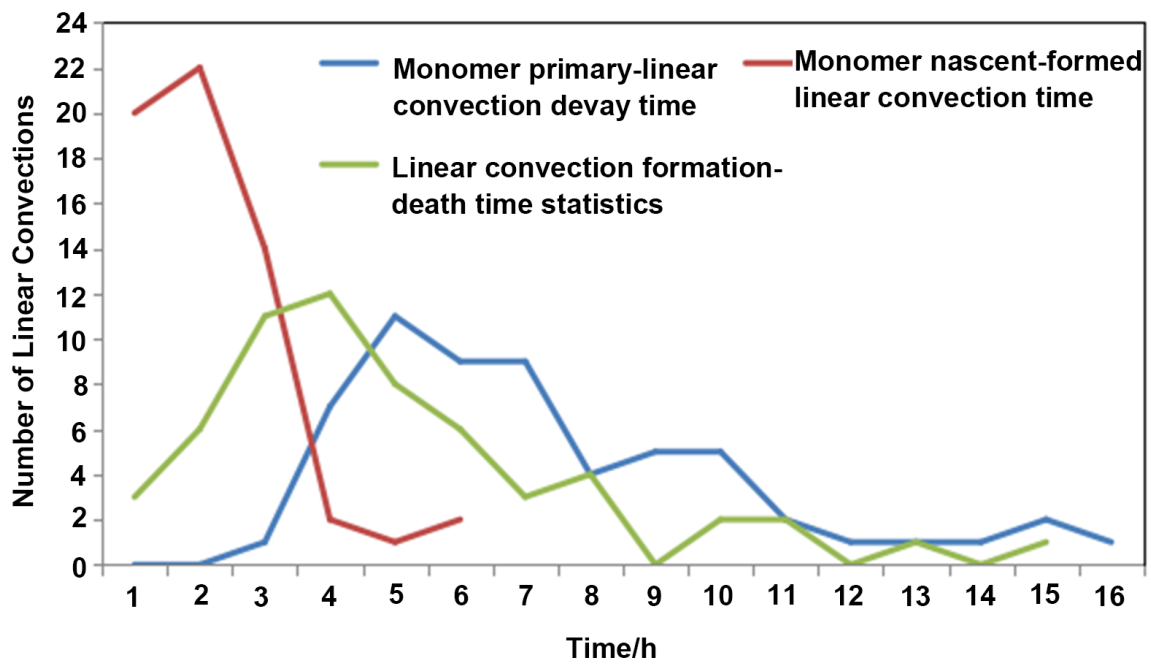

Figure 5. MCS monomer primary-linear convection decay time, monomer nascent-formed linear convection time and linear convection formation-death time statistics.

4) The linear MCS in the continuous heavy rain in Fujian lasted for $4-10$ hours. The formation time of the monomer to form a linear convection time is mainly 1 - 3 hours, which is 2 hours earlier than the organization process of the general linear mesoscale convective system. The linear convective system formed to a dead time of an average of 5 hours, slightly longer than the general linear mesoscale convective system.

\section{Acknowledgements}

This work was supported by Fujian Meteorological Bureau Open Meteorological Science Research Fund Project (No. 2018K02).

\section{Conflicts of Interest}

The authors declare no conflicts of interest regarding the publication of this paper.

\section{References}

[1] Bao, X.W. and Tan, Z.M. (2010) A New Mechanism for the Generation and Development of Convective Monomers in a Two-Dimensional Multi-Monomer Thunderstorm System. Journal of Meteorology, 68, 296-308.

[2] Zheng, Y.G., Chen, J. and Zhu, P.J. (2008) Summer Mesoscale Convective System Distribution and Its Variation Characteristics in China and Surrounding Areas in Summer. Chinese Science Bulletin, 53, 471-481.

[3] Sun, J.H., Zhou, H.G., Zhao, S.X., et al. (2006) An Observational Study of Mesoscale Convective Systems Producing Severe Heavy Rainfall in the Huaihe River Basin during 3-5 July 2003. Chinese Journal of Atmospheric Sciences, 30, 1103-1118.

[4] Blanchard, D.O. (1990) Mesoscale Convective Pattern of the Southern High Plains. Bulletin of the American Meteorological Society, 71, 995-1005.

[5] Bluestein, H.B. and Jain, M.H. (1985) Formation of Mesoscale Lines of Precipitation: Severe Squall Lines in Oklahoma during the Spring. Journal of the Atmos- 
pheric Sciences, 42, 1711-1732.

[6] Parker, M.D. and Johnson, R.H. (2000) Organizational Modes of Mid-Latitude mesoscale Convective Systems. Monthly Weather Review, 128, 3413-3436.

[7] Meng, Z., Yan, D. and Zhang, Y. (2013) General Features of Squall Lines in East China. Monthly Weather Review, 141, 1629-1647.

[8] Tao, S.Y., et al. (1980) Heavy Rain in China. China Science Press, Beijing, 255.

[9] Bao, M. (2007) The Statistical Analysis of the Persistent Heavy Rain in the Last 50 Years over China and Their Backgrounds on the Large Scale Circulation. Chinese Journal of Atmospheric Sciences, 31, 779-792.

[10] Chen, Y. and Zhai, P.M. (2012) Analysis of the Characteristics of Persistent Heavy Rain in China. S1 Disaster Weather Research and Forecast.

[11] Huang, L.N., Gao, J.Y. and Chen, C.Z. (2014) Analysis on Atmospheric Low-Frequency Features of Persistent Heavy Rains During Pre-Flood Season in Fujian. Meteorological Monthly, 40, 723-732.

[12] Mu, J.L., Wang, J.J. and Li, Z.C. (2008) A Study of Environment and Mesoscale Convective Systems of Continuous Heavy Rainfall in the South of China in June 2005. Acta Meteorologica Sinica, 66, 437-450.

[13] Xia, L.H., Yu, C. and He, X.N. (2012) Diagnostic Analysis of a Persistent Severe Convective Weather Process in Fujian Province. Torrential Rain and Disasters, 31, 280-286.

[14] Guo, H., Lin, Y.H. and Wang, S.Q. (2016) Characteristics of Linear Mesoscale Convective System in Continuous Heavy Rain in South China. Fujian Weather, 2.

[15] Haggag, M. and El-Badry, H. (2013) Mesoscale Numerical Study of Quasi-Stationary Convective System over Jeddah in November 2009. Atmospheric and Climate Sciences, 3, 73-86. https://doi.org/10.4236/acs.2013.31010

[16] Sakuno, Y. and Oki, K. (2015) Relationship between Turbid Water and Coral Damage Distribution Using ALOS AVNIR-2 Images and Diving Survey Data Immediately after the Heavy Rain Disaster of the Amami-Oshima Island, Japan. Advances in Remote Sensing, 4, 25-34. https://doi.org/10.4236/ars.2015.41003 